Universidad Diego Portales. Director del Programa de Derecho Público. Director del Departamento de Derecho Público. Santiago, Chile. a'Doctor en Derecho.

Trabajo no recibió financiamiento.

El autor declara no tener conflictos de interés.

Recibido el 12 de abril de 2018, aceptado el 25 de junio de 2018 .

Correspondencia a: Rodolfo Figueroa

Facultad de Derecho, Universidad Diego Portales. República 112. Santiago, Chile. Teléfono: 56-2-26768806 rodolfo.figueroa@udp.cl

\section{Jurisprudencia sobre transfusión de sangre y consentimiento informado de Testigos de Jehová}

\author{
RODOLFO FIGUEROA G. ${ }^{a}$
}

\section{The jurisprudence about blood transfusion and informed consent of Jehovah witnesses}

The law No 20.584 established the informed consent. This could suggest that patients have a right to refuse a blood transfusion. However, the dominant jurisprudence in protection claims filed against Jehovah Witnesses who rejected a blood transfusion, reveals that they do not have such a right. There were two exceptions in 2008, where courts acknowledged the patient's autonomy and denied the petition to authorize a blood transfusion. Most cases precede law $N^{o}$ 20.584. However, those cases which were upheld by the courts after the promulgation of the law, although few, follow exactly the same doctrine as before the appearance of this act.

(Rev Med Chile 2018; 146: 914-917)

Key words: Blood Transfusion; Informed Consent; Jehovah's Witnesses.
¿E stá permitido practicar una transfusión de sangre en un paciente que se opone a ello de manera expresa, como un Testigo de Jehová? Como es sabido, el artículo 14 de la ley no 20.584 reconoce a las personas el "...derecho a otorgar o denegar su voluntad para someterse a cualquier procedimiento o tratamiento vinculado a su atención de salud..."2 Dicho precepto establece la institución del consentimiento informado en nuestro sistema legal ${ }^{3}$, con algunas limitaciones ${ }^{4}$, entre ellas, recurrir al comité de ética del establecimiento de salud cuando la negativa del paciente lo exponga a "...graves daños a su salud o a riesgo de morir, que serían evitables prudencialmente siguiendo los tratamientos indicados..." Una vez que se siga ese procedimiento, sería posible aceptar la voluntad del paciente. Este asunto es relevante para quienes se declaran Testigos de Jehová, pues ellos rechazan la transfusión de sangre por razones religiosas. En teoría, se podría responder en forma negativa la pregunta que inicia este trabajo: no está permitido transfundir a una persona en contra de su voluntad. Desde el punto de vista de la ética médica, algunos autores nacionales también apoyan esa respuesta, como Retamales $^{6}$, Retamales y Cardemil ${ }^{7}$, Bessio $^{8}$, Guerrero 9. Sin embargo, la jurisprudencia de los tribunales chilenos proporciona una respuesta en sentido inverso, a diferencia de lo que indican Retamales ${ }^{5}$ y Guerrero ${ }^{8}$, que señalan que los tribunales apoyan el consentimiento informado, citando un solo caso. Este trabajo muestra dicha jurisprudencia.

\section{Jurisprudencia sobre transfusiones de sangre}

\section{Tendencia dominante}

En Chile ha habido numerosos casos judiciales de transfusiones de sangre que involucraron a pacientes que son Testigos de Jehová (Corte de Apelaciones de Copiapó. 24 de marzo de 1992. Rol No 3.569; Corte de Apelaciones de Rancagua. 22 de agosto de 1995. Rol No 1030; Corte de Apelaciones de Santiago. $1^{\circ}$ de diciembre de 1995. Rol No 3996-1995; Corte de Apelaciones de San Miguel. 11 de enero de 2001. Rol No 334- 
2000; Corte de Apelaciones de Coyhaique. 12 de septiembre de 2002. Rol No 39-2002; Corte de Apelaciones de Santiago, 5 de julio de 2008, Rol No 4.330-2008; Corte de Apelaciones de Copiapó. 9 de agosto de 2008. Rol No 230-08; Corte de Apelaciones de Antofagasta. 3 de octubre de 2008. Rol No 557-2008; Corte de Apelaciones de Valparaíso. 24 de octubre de 2008. Rol No 554-2008; Corte de Apelaciones de Valparaíso. 25 de marzo de 2015. Rol No 977-2015; Corte de Apelaciones de Rancagua. Confirma la Corte Suprema, 16 de marzo de 2017. Rol No 1.764-2017). Se han revisado todos los que es posible hallar en bases electrónicas. ${ }^{10}$ Estas personas se negaban a ser transfundidas, invocando su derecho a la libertad de conciencia y/o de culto, argumentando que sus creencias religiosas ${ }^{11}$ les impedían la transfusión. Dado que ese procedimiento era considerado indispensable para salvar la vida del paciente, los directores de los centros de salud interpusieron recursos de protección en contra de los pacientes, pero en favor de ellos mismos, invocando el derecho a la vida de sus pacientes. Las cortes casi siempre acogieron los recursos, apoyándose en el derecho a la vida, dándole primacía sobre la libertad de culto o de conciencia. Por ejemplo, en un caso se sostuvo:

"[s]e acoge el recurso de protección (...) y se ordena oficiar al Director Ejecutivo (...) para que éste o quien lo subrogue, disponga aplicar, aun contra la voluntad del enfermo (...) y de algunos de sus familiares, la terapia que sea necesaria para la enfermedad que éste padece, incluida la transfusión sanguínea, si ella fuere necesaria, para recuperar su salud y mantenerlo con vida." (Corte de Apelaciones de Rancagua. 22 de agosto de 1995. Rol No 1030).

En ocasiones, las cortes reconocen que el médico tiene un deber como profesional de salvar la vida de paciente o actuar según su propia conciencia (Corte de Apelaciones de Copiapó. 24 de marzo de 1992. Rol No 3.569). Por ejemplo, en otro caso, la corte sostuvo:

"Que constituye una obligación de los médicos tratantes de la persona en cuyo favor se ha recurrido, el procurar por todos los medios y técnicas que integran la lex artis médica el mantener la vida de sus pacientes utilizando la transfusión de sangre cuando ello fuere necesario, aun contra la voluntad del paciente y de sus familiares que por motivos religiosos se niegan a aceptar tal trata- miento..." (Corte de Apelaciones de Rancagua. 22 de agosto de 1995. Rol No 1030).

\section{Excepciones del año 2008}

El año 2008 hubo dos casos en los cuales las cortes reconocieron el derecho del paciente a no someterse a una transfusión sanguínea. En el primero, la corte declaró que:

"[c] ada persona, en la esfera de sus legítimas decisiones, puede adoptar la forma de vida, las creencias y opciones religiosas que estime del caso, y conducirse conforme a tal determinación, en la medida que con ello no afecte el derecho de otros y, en cuanto ejercicio de derechos legítimos, resulta un deber del Estado y sus órganos, respetar el conjunto de opciones y creencias que las personas adopten en tal ejercicio. Por lo mismo, si ya la decisión de someterse a un tratamiento médico determinado, en la medida que la decisión se adopte libre, consciente e informadamente, cae en la esfera de las decisiones personales y, consecuentemente, merece respeto y protección constitucional, cualesquiera que sea la motivación del paciente, la negativa a recibirlo, ahora por consideraciones -o si se quiere prohibiciones- de tipo religioso, aún más merecen dicho respeto y protección en cuanto ejercicio del derecho a la libertad de conciencia, manifestación de creencias y libre ejercicio de culto, garantido en la Constitución..." (Corte de Apelaciones de Copiapó. 9 de agosto de 2008. Rol No 230-08, Co 2).

Ahora bien, la corte efectuó una distinción en este caso: si el paciente entra en estado de inconsciencia y, por ello, no puede manifestar su voluntad, dicha voluntad debe ser suplida por la corte, y debe serlo en el sentido de proteger la vida del paciente, de modo que puede autorizar la transfusión (Corte de Apelaciones de Antofagasta. Rol No 557-2008, Co 8). En el segundo caso del año 2008, la corte no efectuó ninguna distinción y simplemente rechazó el recurso de protección interpuesto por el establecimiento de salud, amparándose en el derecho de autonomía del paciente y negando autorización para la trasfusión:

"[e]n el presente caso no puede entenderse que la propia recurrida haya incurrido en un acto que pone en peligro su derecho a la vida, que merezca ser objeto de protección constitucional, en circunstancias que ha sido ella misma quien expresamente ha resuelto y determinado que no desea someterse a transfusión de sangre alguna, 
ello en uso de su libertad personal y de acuerdo con creencias religiosas que menciona expresamente." (Corte de Apelaciones de Antofagasta, Rol No 557-2008, Co 8).

Cabe señalar que estos dos únicos casos que reconocen la autonomía del paciente no llegaron a la Corte Suprema. Por tanto, esta doctrina no ha sido validada por el máximo tribunal.

\section{El testamento vital}

En un par de casos, los pacientes presentaron lo que puede denominarse un testamento vital, en el cual declaraban que se oponían expresamente a la transfusión de sangre. En el primer caso, la corte no respaldó el testamento vital y autorizó proceder contra la voluntad del paciente (Corte de Apelaciones de Rancagua, 11 de febrero de 2008. Rol No 1034, Co 1). En el segundo caso, en sentido inverso, la corte basó por completo su fallo en el testamento vital, respetando la voluntad del paciente y rechazando el recurso interpuesto por el médico, declarando: "...ha quedado en evidencia que la paciente (...), manifestó con claridad y en forma expresa ante Notario Público su negativa a someterse al tratamiento de transfusión de sangre..." (Clínica Antofagasta, Rol No 557-2008, Co 8 ). La corte estimó que esta manifestación de voluntad debe primar sobre el derecho a la vida (Clínica Antofagasta, Rol No 557-2008, Co 8).

\section{Los recién nacidos}

Ha habido varios recursos de protección (Corte de Apelaciones de Rancagua. 11 de febrero de 2008. Rol No 1034; Corte de Apelaciones de San Miguel. 22 de mayo de 2004. Rol No 123-2004; Corte de Apelaciones de Santiago. 7 de agosto de 2008. Rol No 2336-2008; Corte de Apelaciones de Valparaíso. 13 de noviembre de 2013. Rol No 6773-2013; Corte de Apelaciones de Concepción. 9 de octubre de 2015. Rol No 6735-2015) en los cuales el paciente es un recién nacido que necesita transfusión sanguínea y sus padres se oponen a ella por ser Testigos de Jehová. En estos casos, cuando ha habido peligro para el menor, las cortes siempre se han autorizado la transfusión de sangre. Por ejemplo, en uno de ellos la corte declaró:

"Que, por sobre cualquiera objeción de conciencia que pudiera asistir a los padres del niño (...), no puede olvidarse que los mismos son personas distintas a su hijo, quien es un ser único y autónomo, a cuyo respecto sus progenitores tienen el deber fundamental de velar por su bienestar y, ante la disyuntiva de que su decisión se contraponga al interés de éste-qué más contrapuesto a los mismos, que la circunstancia de ver en peligro su vida por la decisión de sus padres- toca a esta Corte, haciéndose cargo del imperativo llamado que realiza la Convención Internacional sobre Derechos del Niño, acoger el recurso intentado, adoptando todas aquellas medidas que importen amparar el interés superior del niño, representado en este caso por su legítimo derecho a recibir la asistencia médica necesaria y oportuna para seguir con vida y poder, en el futuro, gozar de todos y cada uno de los derechos inherentes a su calidad de persona." (Corte de Apelaciones de Rancagua. 11 de febrero de 2008. Rol No 1034, Co 1).

Sin embargo, en uno de esos casos en que estaba involucrado un recién nacido (Corte de Apelaciones de San Miguel. 22 de mayo de 2004. Rol No 123-2004), los padres se opusieron a la transfusión de sangre no sólo porque ellos eran Testigos de Jehová sino además porque el niño era prematuro y la transfusión era riesgosa; junto con ello, indicaron que ese procedimiento implicaba riesgos de contagio de enfermedades. Los padres solicitaron al hospital que recurriera a tratamientos alternativos, como Eritropoyetina, citando experiencias clínicas en que habían sido exitosas en Chile. La corte accedió a contactar a los profesionales mencionados por los padres, para que iniciaran ese procedimiento. En la práctica y ante la emergencia, se practicó transfusión al menor, pero también se inició el tratamiento alternativo. Finalmente, la corte rechazó el recurso, declarando que no se debía continuar con la transfusión de sangre. Además, sugirió al Servicio de Salud implementar, en lo posible, el tratamiento alternativo empleado u otro semejante. Esta sugerencia fue dejada sin efecto por la Corte Suprema (Corte Suprema, Rol No 123-2004, apelación del caso de 22 de mayo de 2004).

\section{La ley No 20.584}

Bajo la vigencia de esta ley, ha habido muy pocos recursos de protección. Tal vez, los médicos no están recurriendo en contra de sus pacientes Testigos de Jehová, aunque determinar eso requiere un estudio empírico. Sin embargo, los pocos casos 
que ha habido, confirman la jurisprudencia precedente. Por ejemplo, el año 2015, en un fallo de 14 líneas, la corte ni siquiera alude a la ley no 20.584 ni al consentimiento informado y determina que la paciente "...no puede disponer de su vida por lo que su negativa a someterse a un procedimiento que le salvaría la vida resulta ilegal (...) que la libertad de conciencia se encuentra limitada por un derecho superior, que es el derecho a la vida" (Corte de Apelaciones de Valparaíso, Rol No 9772015, Co 3) y se acoge el recurso, autorizando al hospital a realizar "...todos los procedimientos (...) y en caso de ser estrictamente necesario, incluir las transfusiones de sangre para proteger y preservar la vida y salud de la paciente." (Corte de Apelaciones de Valparaíso, Rol No 977-2015, Co 3) Esta sentencia no fue apelada ante la Corte Suprema.

\section{Conclusiones}

i) La jurisprudencia dominante de las cortes permite responder en forma afirmativa la pregunta de este trabajo: sí está permitido transfundir a una persona contra su voluntad, aunque sean Testigos de Jehová que invoquen su derecho a la libertad de conciencia y de culto. El derecho a la vida prima sobre los demás derechos. De 11 casos registrados, en 9 las cortes fallaron contra los Testigos de Jehová y sólo en 2 del año 2008 reconocieron la autonomía de los pacientes y el derecho a rechazar un tratamiento médico como la transfusión de sangre. Además, esta doctrina minoritaria no ha sido confirmada por la Corte Suprema; en cambio, la postura mayoritaria sí lo ha sido en reiteradas oportunidades. ii) La doctrina dominante no tiene excepciones tratándose de recién nacidos, en que son los padres quienes se oponen a la transfusión de sangre por razones religiosas.

iii) La entrada en vigencia de la ley no 20.584 no ha impedido a las cortes -aunque sean pocos casos- prescindir de la autonomía de los pacientes y del consentimiento informado y autorizar la transfusión de sangre contra la voluntad de los Testigos de Jehová.

\section{Referencias}

1. Artículo 4 inciso $1^{\circ}$, Ley No 20.584. https://www.leychile. cl/Navegar?idNorma $=1039348$ \& buscar $=20584$.

2. Figueroa R. Consentimiento informado en la nueva ley de derechos de los pacientes. Rev Med Chile 2012; 140: 1347-51.

3. Artículos 14, 15, 16, 17 y 18 de la ley No 20.584. https:// www.leychile.cl/Navegar?idNorma $=1039348 \&$ buscar $=20584$.

4. Artículo 17 de la No 20.584. https://www.leychile.cl/ Navegar?idNorma $=1039348 \&$ buscar $=20584$.

5. Retamales A. Autonomía del paciente: los Testigos de Jehová y la elección de alternativas a la transfusión. Rev Chil Obstet Ginecol 2006; 71 (4): 280-7.

6. Retamales A, Cardemil G. Beneficios del ejercicio de la autonomía y consentimiento informado: ejemplo de los Testigos de Jehová. Rev Med Chile 2009; 137: 1388-94.

7. Bessio M. Testigos de Jehová y transfusión sanguínea. Reflexión desde una ética natural. Rev Chil Obstet Ginecol 2006; 71 (4): 274-9.

8. Guerrero M. Enfrentamiento médico legal del paciente Testigo de Jehová. Rev Med Clin Condes 2011; 22 (3): 397-403.

9. Legal Publishing Thomson Reuters; Microjuris y Poder Judicial.

10. La Biblia, Génesis, cap. 9, versículo 4. 